\title{
Design and test of bionic wide-ridge soybean tilling-sowing machine
}

\author{
Honglei Jia ${ }^{1,2}$, Mingzhuo Guo ${ }^{1,2}$, Jiale Zhao ${ }^{1,2^{*}}$, Dongyan Huang ${ }^{1,2}$, Jian Zhuang ${ }^{1,2}$, Jiangtao $\mathrm{Qi}^{1,2}$ \\ (1. College of Biological and Agricultural Engineering, Jilin University, Changchun 130022, China; \\ 2. Key Laboratory of Bionic Engineering, Ministry of Education, Jilin University, Changchun 130022, China)
}

\begin{abstract}
The insufficient accumulated temperature of the plow layer during spring tillage in Northeast China severely restricts soybean root growth and whole-plant development. High regional soil viscosity further complicates tilling-sowing. In order to seek a solution to these problems, field comparative tests were conducted to investigate the effects of shallow-loosening (SL) and reshaping ridge (RR) on soil temperature and soybean root growth. Compared with conventional tillage (CT), SL and RR significantly increased the soil temperatures within $0-25 \mathrm{~cm}(p<0.05)$ and $0-15 \mathrm{~cm}(p<0.05)$, respectively. In particular, higher soil temperature within $15-25 \mathrm{~cm}$ was established after SL than after RR $(p<0.05)$. Additionally, SL promoted substantially more vigorous soybean development (seedling height) than $\mathrm{RR}(p<0.05)$, which in turn led to a significant outperformance over CT $(p<0.05)$. Further, bionics, reverse engineering, and curve fitting were combined to design a hare claw toe bionic shallow-loosening shovel and a pangolin scale bionic ridging shovel with anti-drag functions. Field verification tests confirmed that these two bionic tillage devices outperformed the conventional tillage device in reducing tractive drag by $13 \%-19 \%$. Based on the results of these tests, a 2BGD-6(110) bionic wide-ridge soybean tilling-sowing machine was designed, which was capable of shallow-loosening, reshaping ridge and sowing. The new machine significantly reduced the tractive drag, efficiently loosened the soil, increased soil temperature, and accelerated soybean root growth. This study can provide a theoretical and practical reference for soybean production in Northeast China.
\end{abstract}

Keywords: bionics, tillage, shallow-loosening, soybean, reshaping ridge, soil temperature

DOI: $10.25165 /$ j.ijabe.20191201.4014

Citation: Jia H L, Guo M Z, Zhao J L, Huang D Y, Zhuang J, Qi J T. Design and test of bionic wide-ridge soybean tilling-sowing machine. Int J Agric \& Biol Eng, 2019; 12(1): 42-51.

\section{Introduction}

Northeast China is the largest soybean-planting region of China, with constituting approximately $50 \%$ of its planting areas and yields. However, compared with ripe, maize, and other high-yield crops, soybean-planting cultivation is limited by the low yield and economic benefits. Moreover, the import of transgenic soybeans has caused a continuous decline in the soybean-planting areas in Northeast China. Thus, efficient ways of safeguarding soybean production in China are sought, such as an improvement of per-unit-area soybean production and a reduction of production costs.

Soybeans in Northeast China are usually planted in the maize-soybean crop rotation. The presence of maize residues necessitates soil preparation before soybean-planting. However, due to the short frost-free period in Northeast China, soybean-planting farmers have to "race against time". Thus, the use of a tilling-sowing machine during tilling, soil preparation, and

\section{Received date: 2017-12-11 Accepted date: 2018-11-04}

Biographies: Honglei Jia, PhD, Professor, research interests: bionic intelligent agricultural machinery and conservation tillage technology, Email: jiahl@vip.163.com; Mingzhuo Guo, PhD, research interests: conservation tillage technology, Email: guomingzhuo@outlook.com; Dongyan Huang, PhD, Professor, research interests: intelligent agricultural machinery, Email: cchdy760829@sina.com; Jian Zhuang, PhD, Associate Professor, research interests: biomimetic materials engineering, Email: zhuangjian@163.com; Jiangtao Qi, PhD, Associate Professor, research interests: intelligent agricultural machinery, Email: qijiangtao@jlu.edu.cn.

*Corresponding author: Jiale Zhao, $\mathrm{PhD}$, Associate Professor, research interests: conservation tillage technique and agriculture mechanization design. Key Laboratory of Bionic Engineering (Ministry of Education), Jilin University, Changchun 130022, China. Tel: +86-18843165417, Email: zhaojiale0313@163.com. sowing would reduce the times and costs of operations, prolong soybean development time, and improve production efficiency ${ }^{[1]}$. In recent years, extensive investigations have been conducted on the development of a tillage-sowing machine to be used in Northeast China. For instance, the 2BJG-12 precision tilling-sowing machine, designed by Heilongjiang Bayi Agricultural University (Daqing, China), is capable of double-row precise spot-sowing in the ridge and layered fertilization. Additionally, the 2BZ-8 soybean precision tilling-sowing machine developed by Heilongjiang Institute of Agricultural and Sideline Products Processing Mechanization has the capability to apply separately seed and base fertilizers and provide zero-speed seed dropping, as well as to adapt to high-speed sowing. In the 2BG-2 rolling disc-typed tilling-sowing machine designed by Shenyang Agricultural University (Shenyang, China), the rolling disc-typed stubble cutters (soil-contact parts) and ridge-clearing parts can be driven without power and are characterized by low soil disturbance rates $^{[2]}$.

In the cool and cold region of Northeast China, the long wintertime soil freezing period and the severe springtime soil freezing jointly cause a deficiency of accumulated temperature in the plow layer, which severely inhibits soybean root growth and reduces soybean emergence rate and thereby soybean yield ${ }^{[3]}$. Shan et al.$^{[4]}$ found that ridge till increased soil temperature, which could modestly relieve the unfavorable impacts. Ma et al. ${ }^{[5]}$ established that ridge till reduced light leakage and improved soil heat absorption and crop yields. Furthermore, the studies of He et al. ${ }^{[6]}$ revealed that the improved reshaping ridge ability was an important indicator of ridging efficiency. Thus, the use of reshaping ridge before sowing could contribute to the formation of well-shaped ridges and the effective increase of ground temperatures.

Tucker $^{[7]}$ found that the soil macropores in the plow layer were 
usually the major channels for plant root interpenetration and water/air motion. Laudicina et al. ${ }^{[8]}$ found shallow-loosening improved the physical-mechanical properties of the plow layer and enhanced soil macroporosity. Therefore, shallow-loosening can promote the air flow capacity and create a favorable environment for soybean growth. Based on the findings of previous studies, herein, we describe the studies and design of a soybean tillage-sowing machine with shallow-loosening and reshaping ridge functions. It was found to improve the pore structures of the plow layer, promote the exchange between the soil and the external air, and accelerate soil temperature accumulation, thereby increasing soybean emergence rates.

Nevertheless, the use of the tilling-sowing machine was limited by large drag and high energy consumption which ascribed to the contact between the working parts and soil. Thus, reducing the friction of soil-contacting parts efficiently effectively improved the operating efficiency. In his investigation Ren proposed that bionic structures could reduce $\operatorname{drag}^{[9]}$. In addition, Ma et al. ${ }^{[10]}$ found that the bionic technique reduced dramatically the drag and was easily designed. Thus, in this study, the bionic anti-drag design was used to optimally develop the geometrical structures of the key soil-contacting parts and thereby to efficiently reduce the working drag. Specifically, a bionic anti-drag shallow-loosening shovel was designed by analyzing the anti-drag structure mechanism of soils excavation by hare claw toes. The surface structural parameters of pangolin scales were measured and used to design the surfaces of a bionic ridging shovel.

Through an innovation integrating the tilling-sowing technique and the bionic anti-drag technique, we designed a bionic wide-ridge soybean tilling-sowing machine. This newly invented tilling-sowing machine could simultaneously perform shallow-loosening, furrowing, fertilization, sowing, reshaping ridge, soil covering, and pressing. Tests of the machine were performed in field conditions in Boli County, Heilongjiang. The effects of tilling-sowing on the soil physical properties and soybean growth were investigated. Furthermore, the anti-drag effects of the bionic hare claw toe and the bionic pangolin scale soil-contacting parts were elucidated. These tests provide valuable information on soybean high-production techniques utilized in Northeast China.

\section{Materials and methods}

\subsection{Design of the complete machine}

Currently, the wide-ridge soybean-planting mode (ridge width $=1100 \mathrm{~mm}$, ridge height $=250 \mathrm{~mm}$ ) is commonly used in Northeast China. Based on this mode, we designed 2BGD-6(110) bionic wide-ridge soybean tilling-sowing machine. This machine consisted of a main frame, a power-driven system, 4 groups of fertilization systems, 12 groups of sowing units, and 7 groups of tilling preparation units. The operation breadth was $6600 \mathrm{~mm}$, and the number of rows was 24 (6 ridges). As can be seen in Figure $1 b$, each group of sowing units was equipped with one set of double-disc furrowing devices, one set of vertical double-cavity seed-metering devices, one set of seeding absence alarm devices, one three-disc extruding soil-covering device, and one real-time pressure detection wheel. The distance between two sowing units was $450 \mathrm{~mm}$. As can be seen in Figure 1c, each group of tilling preparation units was equipped with one soil-breaking roller, one bionic anti-drag shallow-loosening shovel, and one bionic ridging shovel (with pangolin scale surface structure). The distance between units was $1100 \mathrm{~mm}$. All units could be installed according to the specific operational requirements, as described below. For instance, when all tilling preparation units were demounted, this machine was turned into a soybean precision sowing machine; when all sowing fertilizing units were demounted, it was turned into a field tilling preparation machine. The complete 2BGD-6(110) bionic wide-ridge soybean tilling-sowing machine is illustrated in Figure 1; its operational parameters are listed in Table 1.

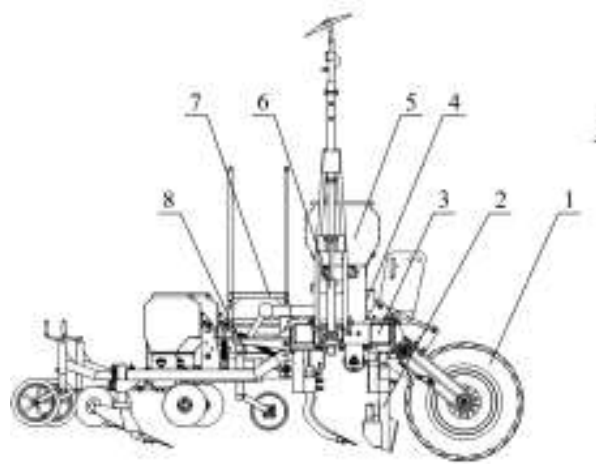

a. Side view of complete machine

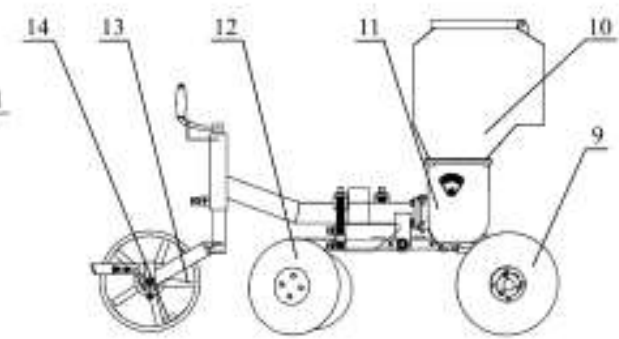

b. Structure of sowing unit

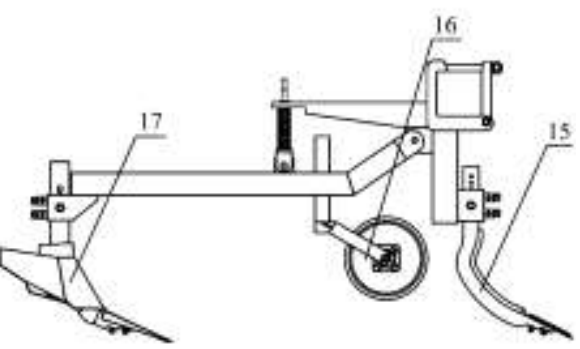

c. Structure of soil tillage and preparation unit

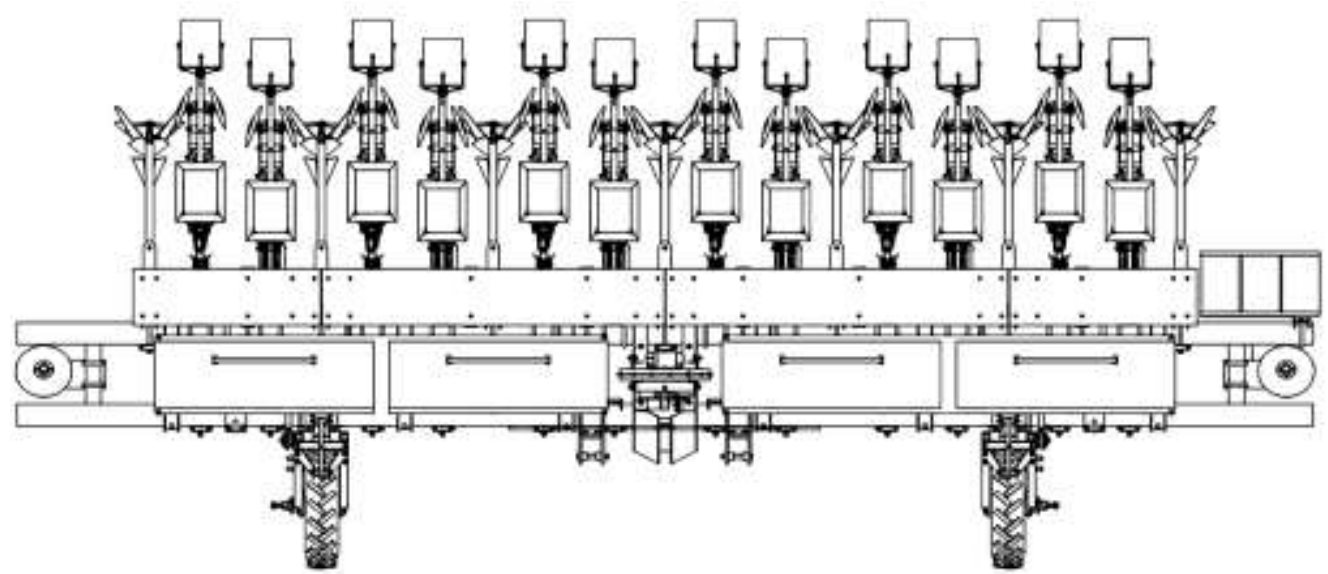

d. Top view of complete machine 


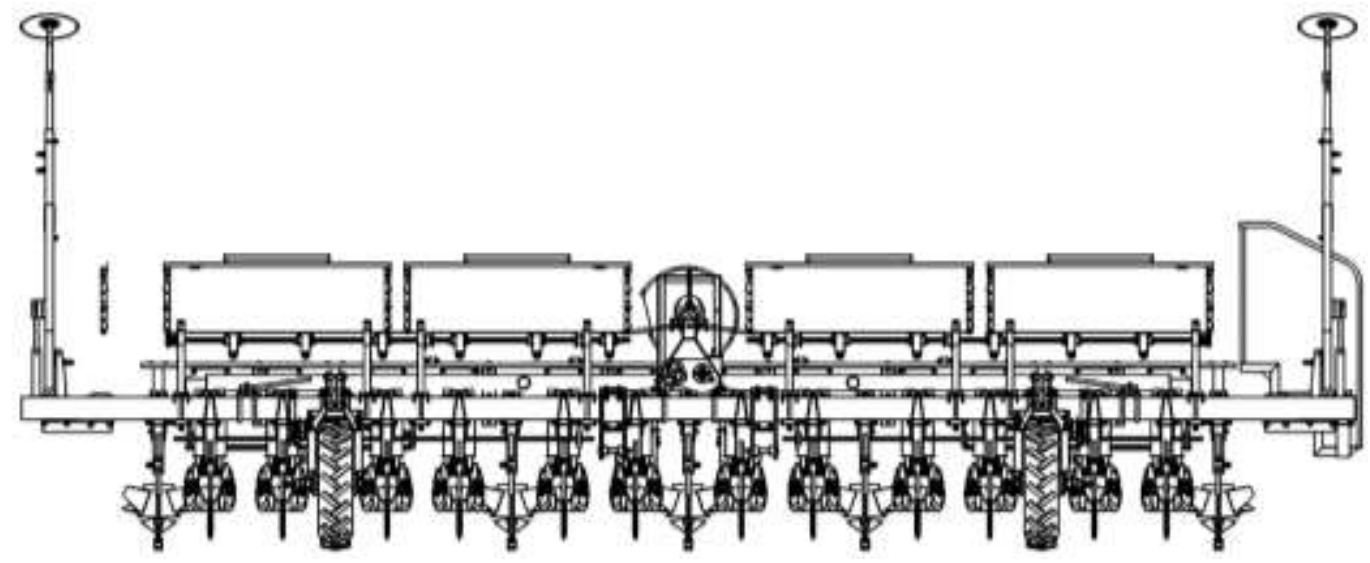

e. Front view of complete machine

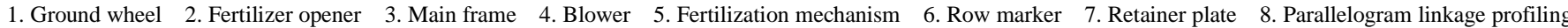
mechanism 9. Double-disc furrowing devices 10. Seed box 11. Vertical double-cavity seed-metering devices 12. Three-disc extruding soil-covering device 13. Press wheel 14. Pressing force collection module 15. Bionic anti-drag shallow-loosening shovel 16. V-shaped soil-breaking roller 17. Bionic ridging shovel

Figure 1 Structure of the complete machine

Table 1 Parameters of the 2BGD-6(110) bionic wide-ridge soybean tilling-sowing machine

\begin{tabular}{|c|c|c|c|c|c|}
\hline No. & Category & Parameter & No. & Category & Parameter \\
\hline 1 & Power/kW & $132.4-154.4$ & 9 & Seed damage rate & $0.2 \%$ \\
\hline 2 & Ridging number & 6 & 10 & Qualification rate of sowing depth & $91.67 \%$ \\
\hline 3 & Ridging spacing/cm & 110 & 11 & Working speed $/ \mathrm{km} \cdot \mathrm{h}^{-1}$ & $5-8$ \\
\hline 4 & Seeding rows & 24 & 12 & Fertilizing amount $/ \mathrm{kg} \cdot \mathrm{hm}^{-2}$ & $100-500$ \\
\hline 5 & Depth of soil Preparation/cm & 20 & 13 & Precision of fertilization & $\geq 94 \%$ \\
\hline 7 & Miss-seeding rate & $3 \%$ & \multirow{2}{*}{15} & \multirow{2}{*}{ Scope of application } & 4 rows sowing on the ridge, \\
\hline 8 & Re-seeding rate & $3 \%$ & & & +soil preparation \\
\hline
\end{tabular}

The driving system of the complete machine was designed in a bilateral independent multistage mechanical chain-driven mode. The ground wheels serve as the power source of the complete machine; the seed-metering devices and the fertilizer devices are driven by the chain-driving system. The power is transferred by the ground wheels to the transmission shaft I, which transfers power to the transmission shaft II and the fertilization shaft. One-stage transmission was set between shaft II and the sowing unit four-bar linkage, namely, the transmission shaft III, which drove the seed-metering shafts to arrange seeds. The schematic diagram of the driving system is illustrated in Figure 2.
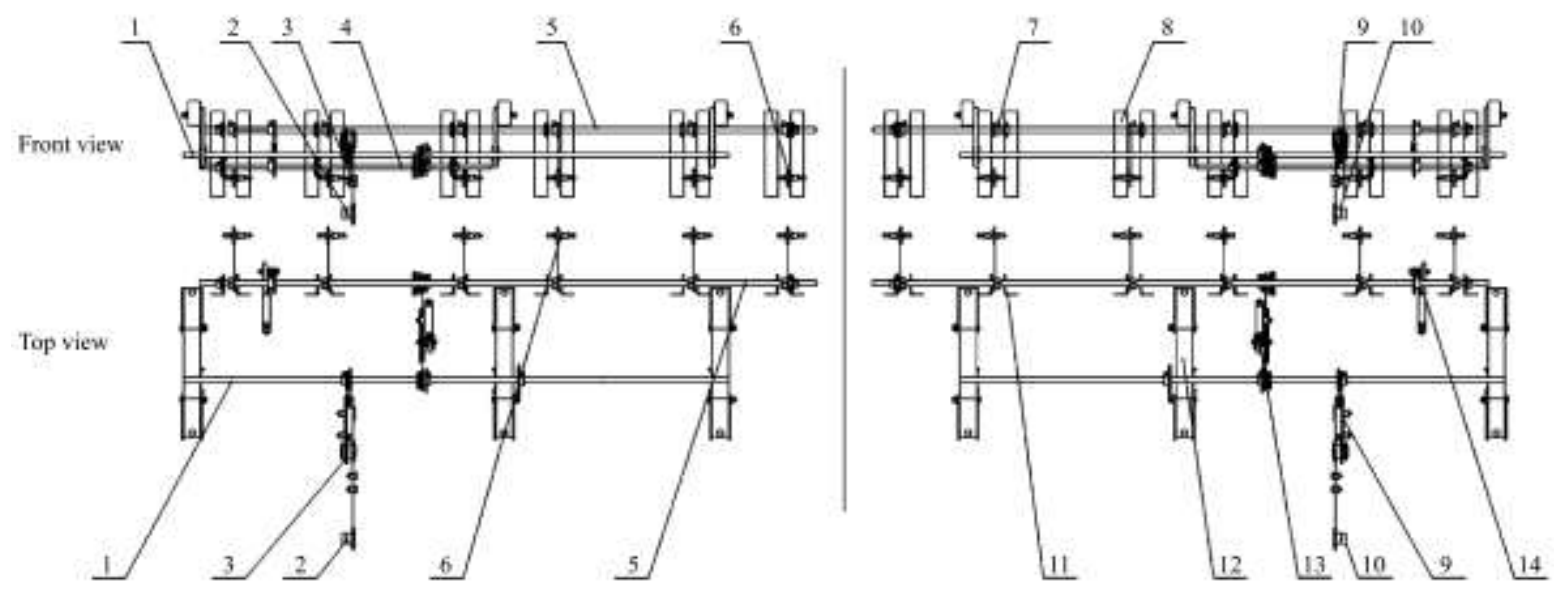

1. Transmission shaft I 2. Left ground wheel shaft 3. Chain-driven device 4. Transmission shaft II 5. Transmission shaft III 6. Seed-metering shaft 7. Chain wheel of seed-metering device 8 . Seed-metering device 9. Tensioning wheel of ground wheel 10. Right ground wheel shaft 11. Bracket of main frame 12. Bracket of fertilizer box 13 . Tensioning wheel of transmission shaft I 14 . Tensioning wheel of transmission shaft II

Figure 2 Transmission system of the complete machine

\subsection{Working mechanism}

When the bionic wide-ridge soybean tilling-sowing machine worked, each group of sowing units operated in one ridge, planting four rows of soybeans in each ridge. Each double-disk furrow opener simultaneously opened two furrows at a space of $220 \mathrm{~mm}$, and each double-cavity pneumatic metering device was capable of double-row intersected sowing ${ }^{[11,12]}$. Sowing is presented in
Figure 3. The row distance on the same ridge was $220 \mathrm{~mm}$, and the between-seed distance was $90 \mathrm{~mm}$. Compared with the conventional wide-ridge double-row planting mode, this machine improved both the sowing density and the sowing distance and reduced the sowing difficulty. After soybean seeds fell into the seed furrows, the three-disc extruding soil-covering device (Figure 4a) simultaneously covered the two furrows with soil. The 
extruding-typed closing and soil covering mode did not alter the structure of the bilaterally distributed soil on the furrows at the plow layer. Afterwards, pressing was initiated. In the real-time pressure detection wheel (Figure 4b), a pressing force collection module was installed inside the wheel walls, which transformed the compression signals into voltage signals, and recorded the real-time

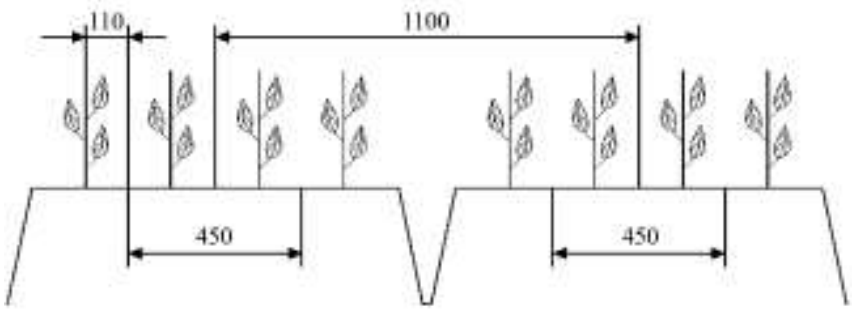

a. Front view of sowing pattern pressing forces and soil compactibility, which ensured the high quality of the pressing operations. Each group of sowing units was set with a seeding absence alarm device (Figure 4c), which monitored the real-time seed-metering conditions; seed-metering amount and speed, sowing area and missing index, thereby ensuring sowing consistency.

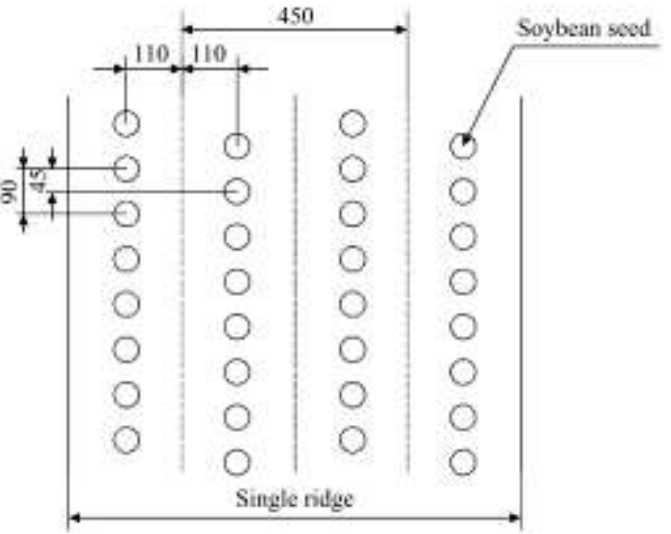

b. Top view of sowing pattern

Figure 3 Sowing pattern diagrammatic sketch

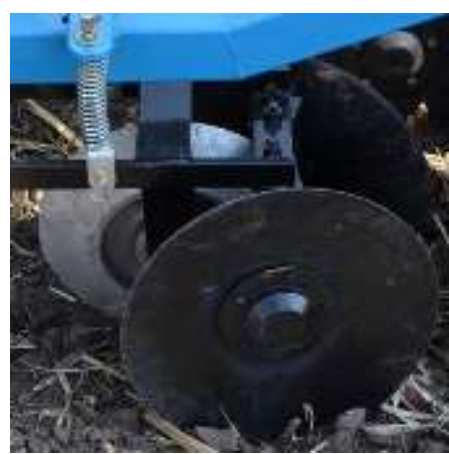

a. Three-disc extruding soil-covering device

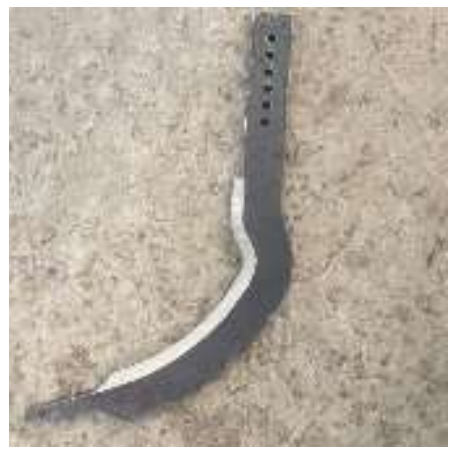

d. Bionic anti-drag shallow-loosening shovel

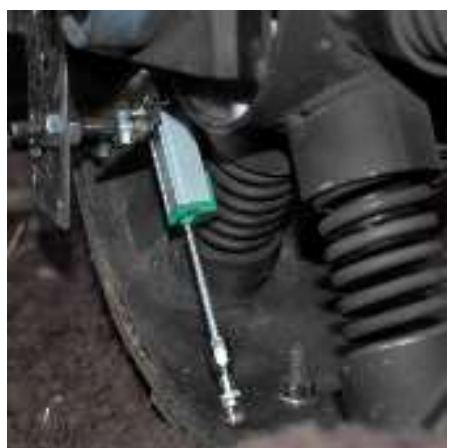

b. Real-time pressure detection wheel

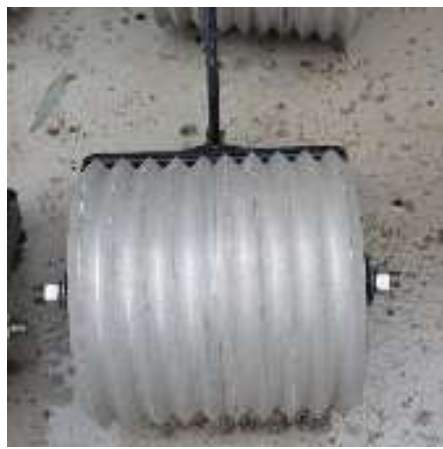

e. V-shaped soil-breaking roller

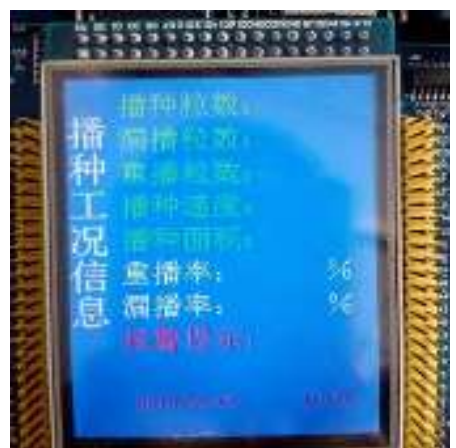

c. Seeding absence alarm device

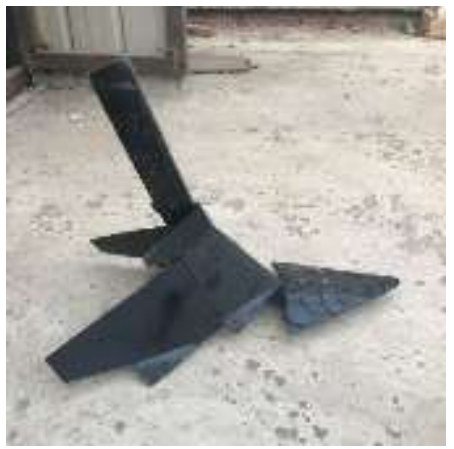

f. Bionic anti-drag shallow-loosening shovel

Figure 4 Structures of the critical parts

When the bionic wide-ridge soybean tilling-sowing machine worked, the soil-breaking rollers of the tilling preparation units operated in ridges, whereas all other parts worked in furrows. Firstly, the bionic anti-drag shallow-loosening shovel (Figure 4d) was used to loosen and break soils; the bionic design of its handle enhanced the penetrating capacity of the shovel and reduced the working drag. The shallow-loosening altered the soil structures of the ground plow layer, and the resulting soil blocks were further broken by the V-shaped soil-breaking roller (Figure 4e), which made the seedbed soil fine and flat, and limited the working depth of the preparation machine. After sowing, the ridging shovel (Figure 4f) was used to trim the initial ridges and improve the ridge shapes. The shovel surfaces were further covered by pangolin scale bionic structures, which effectively reduced the friction during the ridging process.

\subsection{The key component design}

2.3.1 Design of bionic space curve shallow-loosening shovel handle

Hares have excellent soil-excavating ability and their underground burrows are exceedingly structurally complex. When a hare excavates, its hind legs support the body, while front the claws cut and throw the soil; thus, the front toe structure and shape are at their optimal states, which minimizes the drag of soil cutting $^{[13]}$. Thus, in this study, based on the front claw structure, the bionic handle of the shallow-loosening shovel was designed by using the idea of bionic principle. The five front toes are structurally similar in general (Figure 5a) and mainly break soils during soil excavation. Thus, a reverse scanner was used to 
extract the contour line of the first claw toe (Figure 5b). Then a polynomial fitting method was used to reversely extract the contour parameters and obtain a smooth curve. The fitting results of outside contour $\left(Y_{1}\right)$ and inside contour $\left(Y_{2}\right)$ are presented in Figure 5c. The fitting equations are as follows:

$$
\begin{gathered}
Y_{1}=-3.15+4.13 x^{1}-1.07 x^{2}+0.15 x^{3}-0.01 x^{4}+3.32 \times 10^{-4} x^{5} \\
Y_{2}=-29.21+19.40 x^{1}-4.90 x^{2}+0.64 x^{3}-0.04 x^{4}+0.001 x^{5}
\end{gathered}
$$

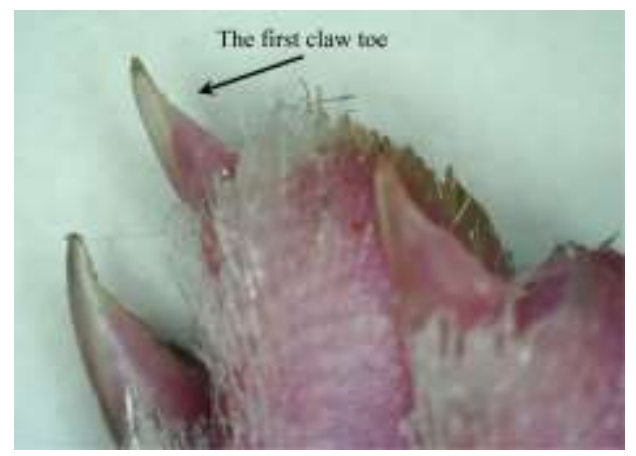

a. Shape of the hare front claw toes

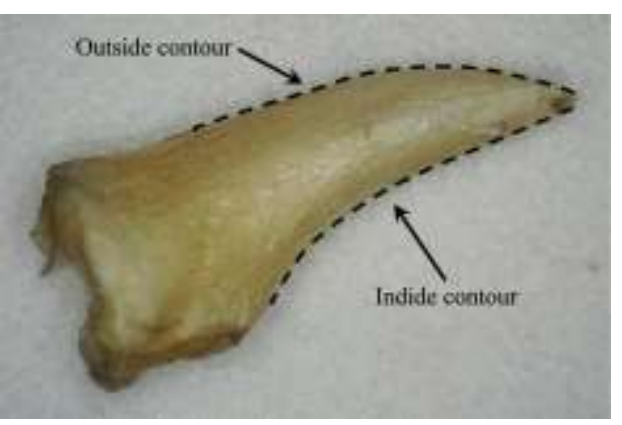

b. Structure of the first claw toe

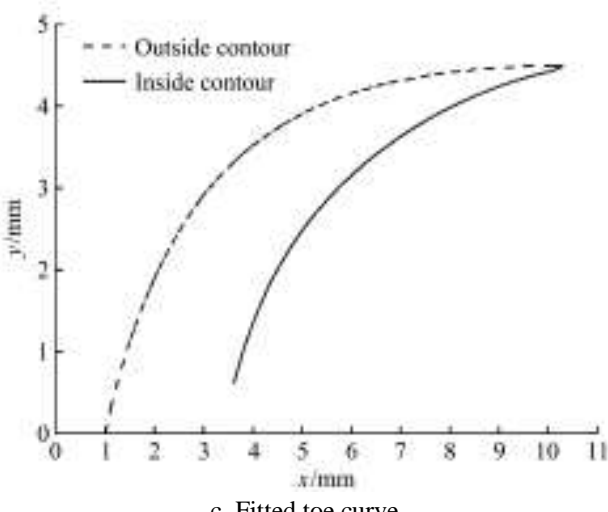

c. Fitted toe curve

Figure 5 Structure of the hare claw toe

The major soil-breaking part of the bionic shallow-loosening shovel is the handle blade, which plows and cuts soils, resulting in large drag. This soil-breaking mode is exceedingly similar to the process that hares front claw toes excavate soil. Thus, the contour curve of the front toes was applied to design a bionic shallow-loosening shovel handle, which reduced the drag and energy consumption during the shallow-loosening.

In the structure of the shallow-loosening shovel (Figure 6), segment $\mathrm{AB}$ is the connecting part between the shovel handle and the main frame, $\mathrm{BC}$ is the soil-breaking blade of the shallow-loosening shovel, and $\mathrm{CD}$ is where the shovel sharp is installed. In particular, segment $\mathrm{BC}$ was designed according to the front toe curve. After the curve modification, the two ends of the segment $\mathrm{BC}$ were smoothly connected to segments $\mathrm{AB}$ and $\mathrm{CD}$, respectively. The section of the blade was designed as a wedge at an included angle of $60^{\circ}$. The depth of shallow-loosening was usually 100-200 mm. To make the shallow-loosening depth consistent with the vertical infiltration of soil moisture, we set an operating depth $\mathrm{L}$ of $200 \mathrm{~mm}$; the handle was $58 \mathrm{~mm}$ wide and $30 \mathrm{~mm}$ thick. The segment $\mathrm{AB}$ was $500 \mathrm{~mm}$ long. The shovel handle was made of $65 \mathrm{Mn}$ steel, and the soil-breaking blade $\mathrm{BC}$ was thermally treated to a hardness of $52 \mathrm{HRC}^{[14]}$. The final product of the shovel handle is shown in Figure $6 \mathrm{~b}$.

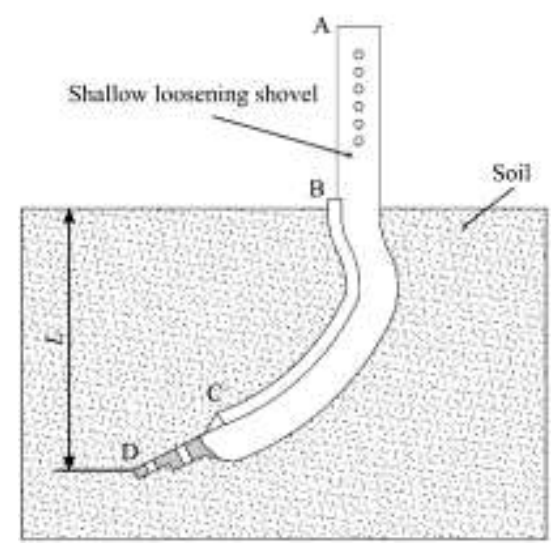

a. shallow loosening shovel model

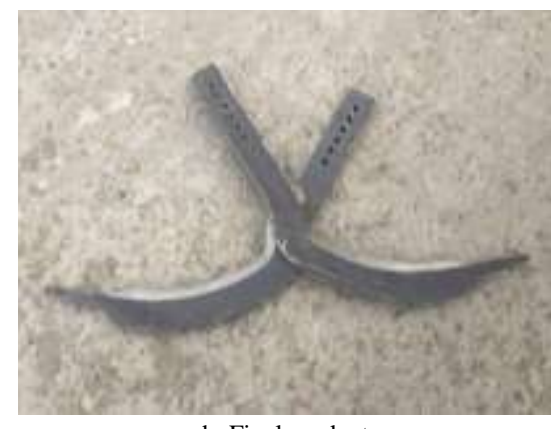

b. Final product

Figure 6 Structure of the bionic shallow-loosening shovel

2.3.2 Design of the coupling bionic anti-drag surface

When the bionic wide-ridge soybean tilling-sowing machine worked, the ridging shovel head plowed and cut soils with certain inclination angles at a depth of $150 \mathrm{~mm}$. Hence, an anti-drag design was applied in ridging shovel to reduce the working drag and power consumption of the complete machine.

We found that the pangolin scales were structurally wave-shaped and the scale layers overlapped (Figure 7a). When the wave-shaped structure contacted the soil, the water films easily became discontinuous even for moisture-sufficient viscous soils, which narrowed the real contact areas on the surfaces and decreased the soil conglutination force. Thus, when the surface structures of the shovel head were designed, the pangolin scale was adopted as a surface morphology to drag reduction ${ }^{[15]}$.

The contours of the pangolin scale were extracted via reverse engineering scanning (Figure 7b), and smooth contour was obtained by the method of approximate treat (Figure 7c). The contour curves of the pangolin scales consisted of an upper curve $L_{1}$ and a lower curve $L_{2}$, and the 2D mathematical model of scale can be expressed as:

$$
\begin{aligned}
& L_{1}: y=a x^{2}+b \\
& L_{2}: y=c x^{2}+d
\end{aligned}
$$

where, $a>0, b>0, b$ is the height of $L_{1} ; c>0, d>0, d$ is the height of $L_{2}$, the formulas call for $b / a=d / c$, the two parabolas that intersect at point $A$ and point $B$ on $x$-axis, $\sqrt{b / a}$ is a half of bottom width of scales, by adjusting the $a, b, c$, and $d$ to simultaneously adjust the height of $L_{1}, L_{2}$ and width of scale, resulting in a more realistic $2 \mathrm{D}$ model. 


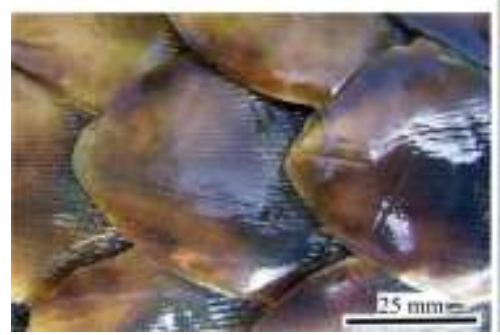

a. Distribution mode of scales ${ }^{[16]}$

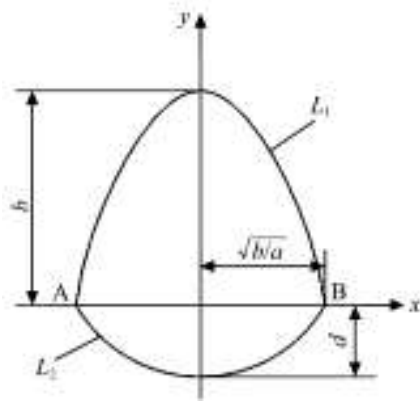

c. 2D mathematical model

Figure 7 Structure of the pangolin scale

According to the volumes of the ridging shovel head, we set $a=0.053, b=37.5 \mathrm{~mm}, c=0.0177, d=12.5 \mathrm{~mm}$, scale thickness $=$ $2 \mathrm{~mm}$; scales were mutually covered by $50 \%$ of areas ${ }^{[17]}$. Given the complicated surface structures of shovels and to ensure the precision and hardness of surface processing, we selected the sand casting method with QT450-10 ductile cast iron as the material and rare earth $\mathrm{Mg}$ alloy as the nodularizer, and performed smelting in an electromagnetic induction stove. The casts were washed with water and cleaned by sand blasting. The coupling bionic anti-drag surface of the ridging shovel head is illustrated in Figure 8.

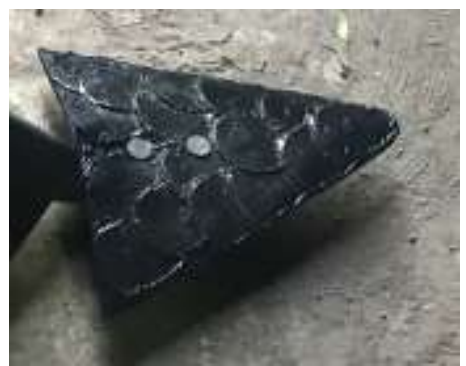

Figure 8 Surface of the bionic ridding shovel

\section{Tests and methods}

\subsection{Test conditions}

Tests were conducted from May 15 to November 10, 2016, in a test base of Boli County, Heilongjiang Province, China (34.07N 70.13E). Field test is schematically presented in Figure 9. This wide-ridge densely-planted soybean base was farmed using the ridge tillage approach. After fall harvest in 2016, this base was deep plowing, tilled, and ridged. The soil properties before spring sowing in 2017 are listed in Table 2.

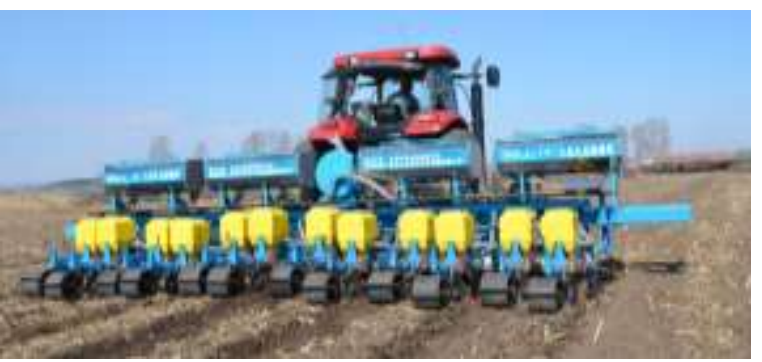

Figure 9 Field test scheme
Table 2 Soil properties within a depth range $0-100 \mathrm{~mm}$ in test field

\begin{tabular}{clc}
\hline No. & \multicolumn{1}{c}{ Properties } & Values \\
\hline 1 & Cone index $/ \mathrm{MPa}$ & 0.913 \\
2 & Volume density $/ \mathrm{g} \cdot \mathrm{cm}^{-3}$ & 1.237 \\
3 & Soil moisture & $21.2 \%$ \\
4 & $\mathrm{pH}$ & 7.08 \\
5 & Organic matter & $3.78 \%$ \\
6 & Total nitrogen & $0.13 \%$ \\
7 & Available $\mathrm{K}\left(\mathrm{K}_{2} \mathrm{O}\right) / \mathrm{mg}^{-3} \mathrm{~kg}^{-1}$ & 173.2 \\
8 & Available $\mathrm{P}\left(\mathrm{P}_{2} \mathrm{O}_{5}\right) / \mathrm{mg}^{-1} \mathrm{~kg}^{-1}$ & 16.5 \\
\hline
\end{tabular}

The main instruments used here were three Case 2104 tractors (power $=210 \mathrm{HP}$, maximum advancing speed $=40 \mathrm{~km} / \mathrm{h}$ ), five 2BGD-6(110) wide-ridge soybean tillage-sowing machines, an SC-900 soil compaction meter, an MS-350 moisture meter, a ring knife assembly (volume $=100 \mathrm{~cm}^{3}$ ), a WQG-16 soil thermometer and an electronic balance.

\subsection{Test methods}

The tests consisted of two parts: study on the effects of shallow-loosening (SL) and reshaping ridge (RR) on soil temperature and soybean development, with machine modes in Table 3, conventional tillage (CT) sowing machine was used as the reference; investigation on the influence of the bionic structure design on the anti-drag performance of tillage sowing, with machine modes in Table 4. Before trials, the field was randomly divided into five equal blocks (A1-A5). Each block had 24 ridges (each $300 \mathrm{~mm}$ high, $1100 \mathrm{~mm}$ wide and $200 \mathrm{~m}$ long). The modes $\mathrm{S} 1, \mathrm{~S} 2$, and $\mathrm{S} 3$ operated in plots $\mathrm{A} 1, \mathrm{~A} 2$, and $\mathrm{A} 3$, respectively. The modes S4 and S5 were used in plots A4 and A5, respectively.

Table 3 Machine modes for shallow loosening and reshaping ridge

\begin{tabular}{cccc}
\hline Mode & SL parts & RR parts & Machine type \\
\hline S1 & No & No & Conventional tillage sowing machine \\
S2 & Yes & No & Shallow-loosening and sowing machine \\
S3 & No & Yes & Reshaping ridge and sowing machine \\
\hline
\end{tabular}

Table 4 Machine modes for anti-drag performance

\begin{tabular}{cccc}
\hline Mode & SL parts & RR parts & Machine type \\
\hline S4 & Bionic & Bionic & Wide-ridge soybean bionic tilling-sowing \\
machine
\end{tabular}

On May 15, 2016, five machines operated simultaneously at the corresponding plots (with sowing pattern as shown in Figure 3). The soybean cultivar Heihe 52 was used in the tests. The fertilizers consisted of urea, diammonium phosphate, and muriate of potash (N:P:K = 1:2:0.5).

\subsection{Measurement of test indices}

Soil temperatures were measured as follows. After the different treatments soil measurements were conducted using a soil thermometer. After sowing on May 20, 2016 and the emergence of all seedlings, soil temperatures at depths $0 \mathrm{~cm}, 5 \mathrm{~cm}, 10 \mathrm{~cm}$, $15 \mathrm{~cm}$, and $20 \mathrm{~cm}$ were measured from June 15 to July 15, 2016. The measurements were performed within 6:00-18:00 every day at an interval of one hour. The mean daily temperature was used in our study ${ }^{[18]}$.

Average seedling height: The consistency of the seedling heights is an important factor that influences crop yield and accurately reflects the effects of crop development conditions ${ }^{[19]}$. The seedling heights were measured at an interval of five days since day 7 after sowing when all seedlings showed up. Seedling 
heights were measured at an interval of five days. Each time, 10 successive seedlings in 10 areas of each plot (A1, A2, and A3) were measured. Calculations were carried out of the average value, standard deviation and $p$-test.

Tractive drag: The anti-drag effects of the bionic shallow-loosening shovel and the surface of bionic ridging shovel on the complete machine were studied. Specifically, the tractive drags of structures S4 and S5 were compared. The tractor and the machine frame were connected through a force transducer. The data were recorded by an agricultural dynamics parameter telemeter at a frequency of $1 \mathrm{~s}^{-1}$. The working speeds of the tractor were $5.3 \mathrm{~km} / \mathrm{h}, 6.5 \mathrm{~km} / \mathrm{h}$, and $7.8 \mathrm{~km} / \mathrm{h}$. The depth of shallow-loosening was fixed at $20 \mathrm{~cm}^{[20]}$.

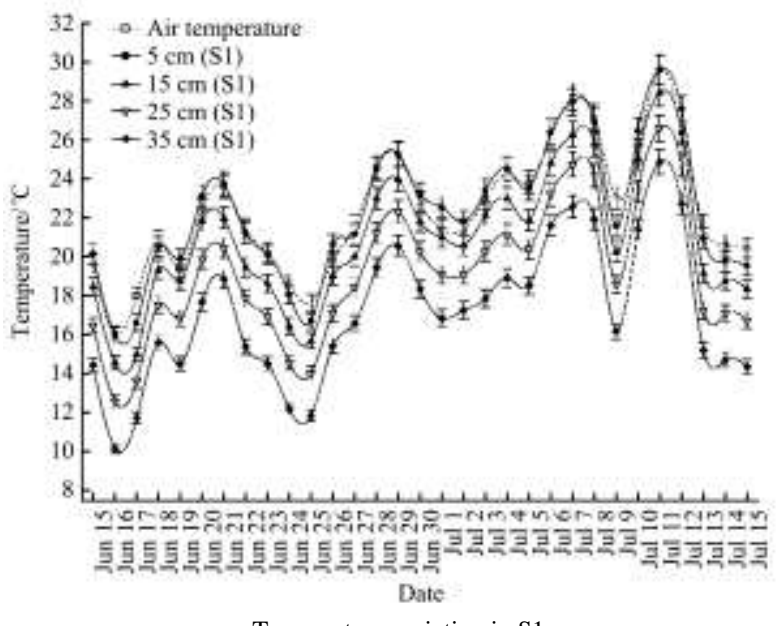

a. Temperature variation in $\mathrm{S} 1$

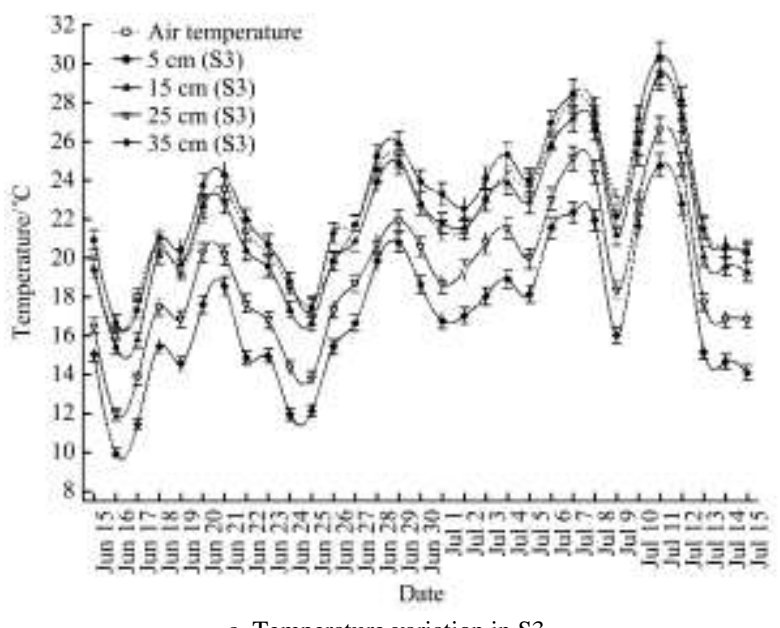

c. Temperature variation in $\mathrm{S} 3$

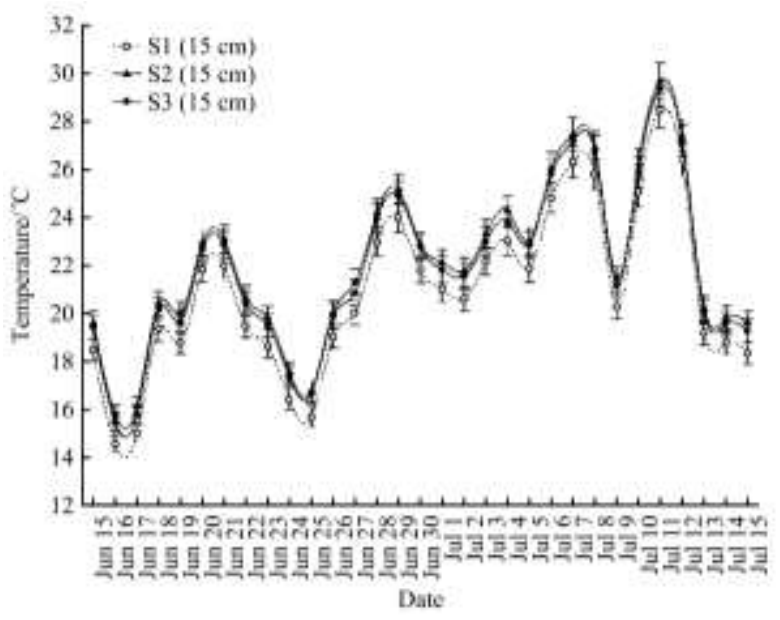

e. Temperature variation at the depth of $15 \mathrm{~cm}$

\section{Results and discussion}

\subsection{Soil temperatures}

The results of soil temperature variation are shown in Figure 10. The soil temperatures of the modes $\mathrm{S} 1, \mathrm{~S} 2$, and $\mathrm{S} 3$ declined to some extents along with the increase of soil depth. This was mainly because the vertical temperature gradient at shallow soil layers outnumbered that of air, and soil thermal capacity was approximately 1000 times that of air. Thus, the greatest part of the heat was absorbed by the plow layer, whereas the heat flux was largely reduced at deep layers. Thus, the soil temperature gradients over these three modes decreased with the increase of soil $\operatorname{depth}^{[21,22]}$.
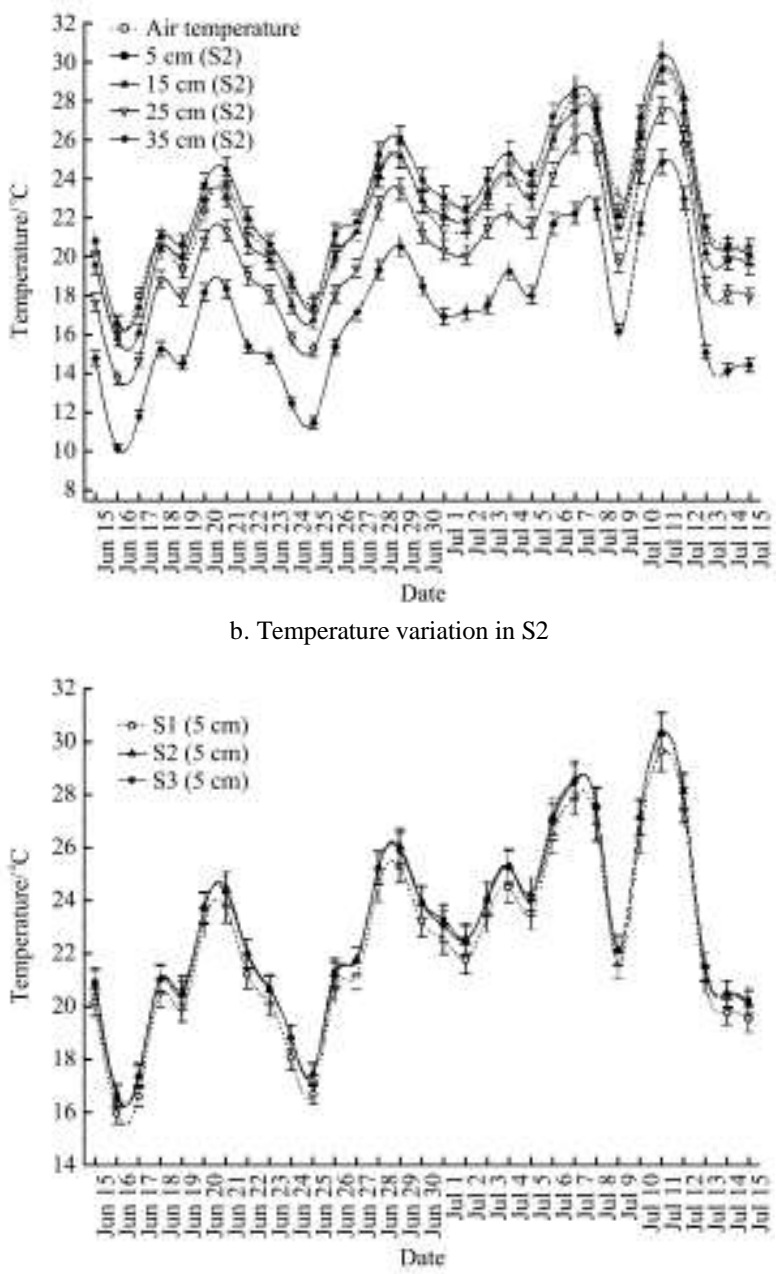

d. Temperature variation at the depth of $5 \mathrm{~cm}$

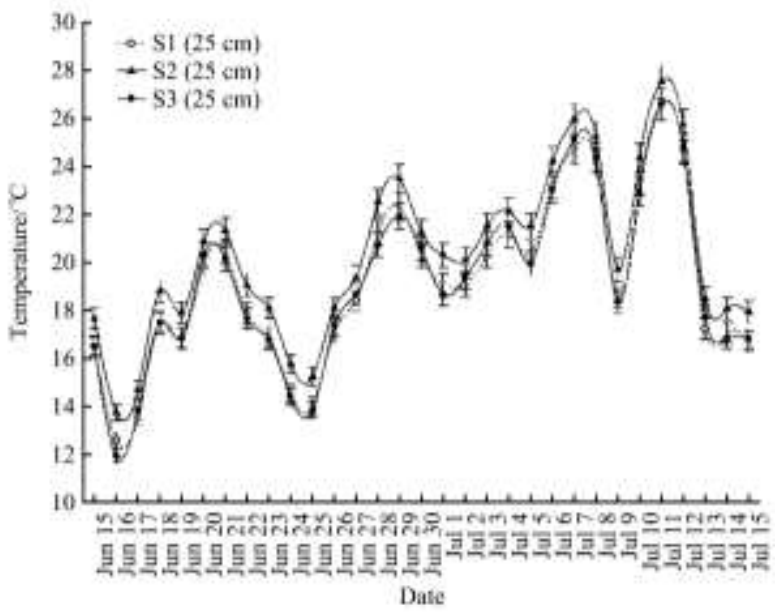

f. Temperature variation at the depth of $25 \mathrm{~cm}$ 


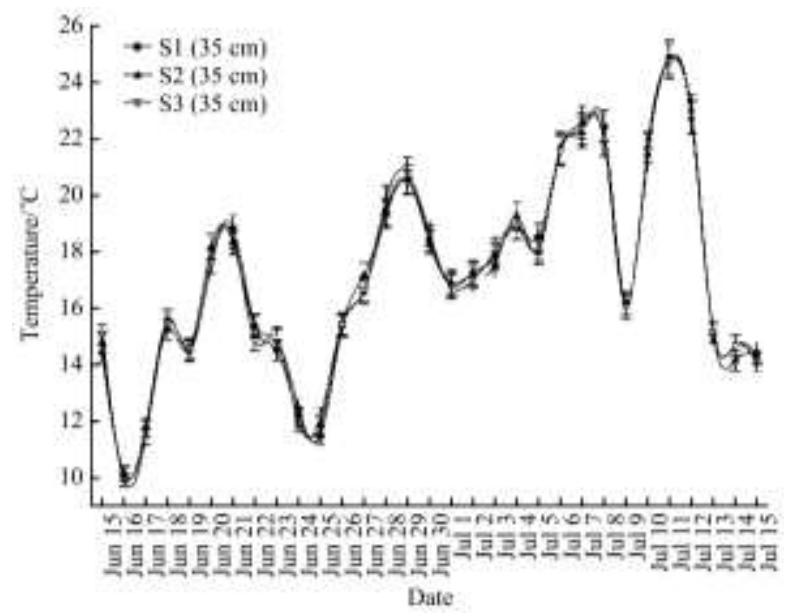

g. Temperature variation in the depth of $35 \mathrm{~cm}$

Figure 10 Results of soil temperature

At a soil depth of $5 \mathrm{~cm}$, the soil temperatures over modes $\mathrm{S} 2$ and S3 were not significantly different, but were significantly higher, by $0.7^{\circ} \mathrm{C}$ and $0.5^{\circ} \mathrm{C}$ respectively, than those over $\mathrm{S} 1$ ( $p<$ 0.05 ). At a soil depth of $15 \mathrm{~cm}$, the soil temperatures over modes S2 and S3 were significantly different $(p<0.05)$ and were both significantly different the case of $\mathrm{S} 1(p<0.05)$; the soil temperature of mode $\mathrm{S} 2$ was higher by $0.6^{\circ} \mathrm{C}$ and $1.3^{\circ} \mathrm{C}$ than those of modes $\mathrm{S} 3$ and S1, respectively. Moreover, at a soil depth of $25 \mathrm{~cm}$, the soil temperatures of mode $\mathrm{S} 2$ were significantly different from those of $\mathrm{S} 1$ and $\mathrm{S} 3(p<0.05)$, but the ones between $\mathrm{S} 3$ and $\mathrm{S} 1$ were not significantly different. The soil temperature of $\mathrm{S} 2$ was higher by $1.2^{\circ} \mathrm{C}$ and $1.3^{\circ} \mathrm{C}$ compared with those of $\mathrm{S} 1$ and $\mathrm{S} 3$. No significant difference was found between any two modes at a depth of $35 \mathrm{~cm}$.

These results suggest that compared with CT, the SL and RR significantly elevated soil temperatures at depths $0-25$ and $0-15 \mathrm{~cm}$, respectively. The SL loosened soil structure and improved soil porosity at the depth $0-20 \mathrm{~cm}$. Thus, increasing soil porosity at the depth $0-20 \mathrm{~cm}$ led to a rise in soil temperature and a modest transfer of heat to the deeper soil layer $(25 \mathrm{~cm})$. Additionally, RR enlarged the illumination areas on soil surfaces, which further increased the temperatures of the surface and underlying soil layer $(15 \mathrm{~cm})$. However, the increase of the soil depth reduced the temperature-raising effects of both operations.

\subsection{Seedling height}

The seedling heights after the use of modes S2 and S3 were both significantly greater than that after the utilization of S1 $(p<$ 0.01 ), and the seedling heights after S2 application were significantly larger than that after S3 use $(p<0.05)$ (Figure 11). On day 35 , the seedling heights over S2 increased by $5.5 \mathrm{~mm}$ relative to $\mathrm{S} 1$, the seedling heights over $\mathrm{S} 3$ increased by $3.1 \mathrm{~mm}$ relative to $\mathrm{S} 1$, the seedling heights over $\mathrm{S} 2$ increased by $2.4 \mathrm{~mm}$ relative to $\mathrm{S} 3$. On day 65 , the seedling heights over $\mathrm{S} 2$ increased by $6.9 \mathrm{~mm}$ relative to $\mathrm{S} 1$, the seedling heights over $\mathrm{S} 3$ increased by $3.7 \mathrm{~mm}$ relative to $\mathrm{S} 1$, the seedling heights over $\mathrm{S} 2$ increased by $3.2 \mathrm{~mm}$ relative to $\mathrm{S} 3$. On day 100 , the seedling heights over $\mathrm{S} 2$ increased by $7.7 \mathrm{~mm}$ relative to $\mathrm{S} 1$, the seedling heights over $\mathrm{S} 3$ increased by $3.5 \mathrm{~mm}$ relative to $\mathrm{S} 1$, the seedling heights over $\mathrm{S} 2$ increased by $4.2 \mathrm{~mm}$ relative to $\mathrm{S} 3$.

The above-discussed results suggest that compared with CT, SL and RR can both facilitate soybean development by raising soil temperatures. Moreover, SL could also loosen soils at the plow layer and thereby provides favorable conditions for soybean root growth, which improves the water and air circulation around the roots $^{[23]}$. Thus, SL more significantly facilitates soybean development than RR.

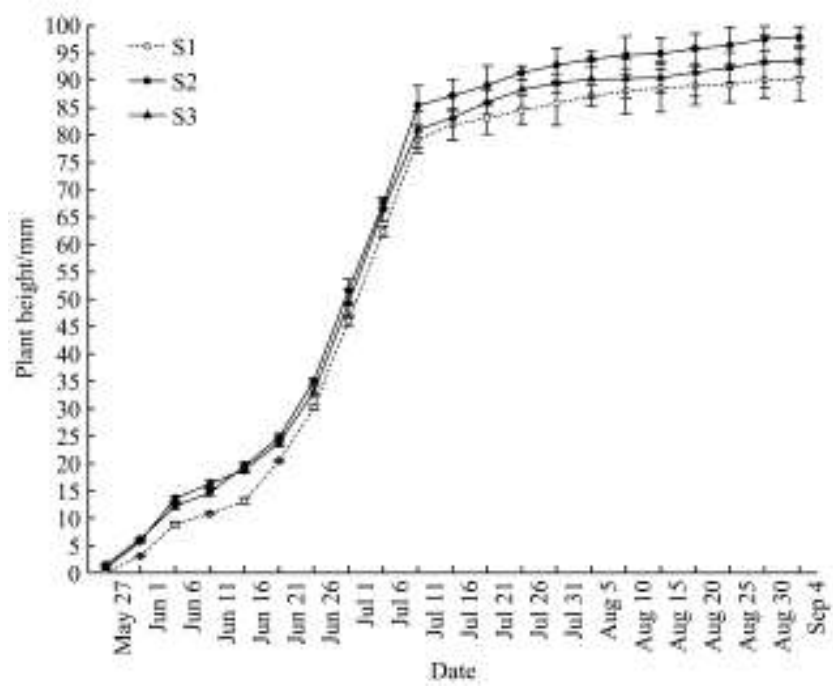

Figure 11 Results of Seedling height

\subsection{Tractive drag}

The results of tractive drag are depicted in Figure 12. During the process of test, the tractive drag rose rapidly, reaching its peak value at the initial stage and then gradually stabilized. This change indicated that when SL and RR parts contacted the soil, the soil-imposed load on these soil-contacting parts was exceedingly small, and the soils were elastically deformed. Nevertheless, when the load was gradually increased and exceeded the soil elasticity limit, the soils entered the plastic deformation stage. As the shallow-loosening shovel and the ridging shovel advanced slowly, the loads imposed on the soil further increased and soils started to yield but not destroyed. At this moment, the soils started to harden, and the tractive drag was maximized (peaks shown on the Figure 12). At this point, the cohesion binding bonds were destroyed, so the soils initially failed and became softer and weaker. The drags faced by the shallow-loosening shovel and the ridging shovel was gradually reduced and stabilized;

Under the same speeds, the peak tractive drag of S4 was significantly smaller and appeared more quickly than that of S5. However, as the speed increased, the peak tractive drag of S4 stepwise approached that of S5. For instance, at the working speed of $5.3 \mathrm{~km} / \mathrm{h}$, the peak tractive drag of $\mathrm{S} 4$ was smaller by $1.69 \mathrm{kN}$ than that of $\mathrm{S} 5$, and the decreasing amplitude was approximately $19 \%$. At the working speed of $6.5 \mathrm{~km} / \mathrm{h}$, the peak 
tractive drag of S4 was lower than that of S5, by $1.48 \mathrm{kN}$, with a decreasing amplitude of about 15\%. At the working speed of $7.8 \mathrm{~km} / \mathrm{h}$, the peak tractive drag of S4 was smaller by $1.37 \mathrm{kN}$ than that of S5, and the decreasing amplitude was approximately $13 \%$.

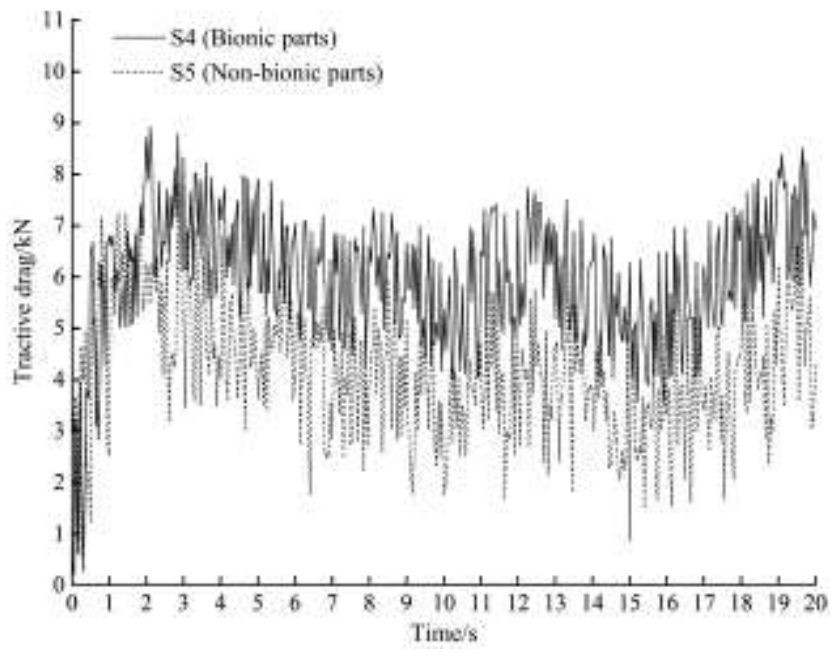

a. Tractive drag at speed of $5.3 \mathrm{~km} / \mathrm{h}$

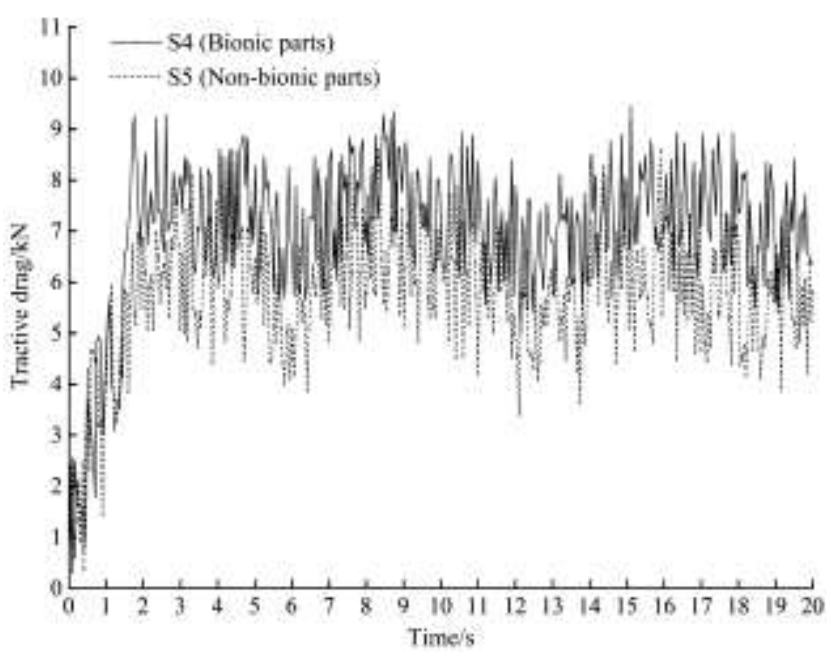

b. Tractive drag at speed of $6.5 \mathrm{~km} / \mathrm{h}$

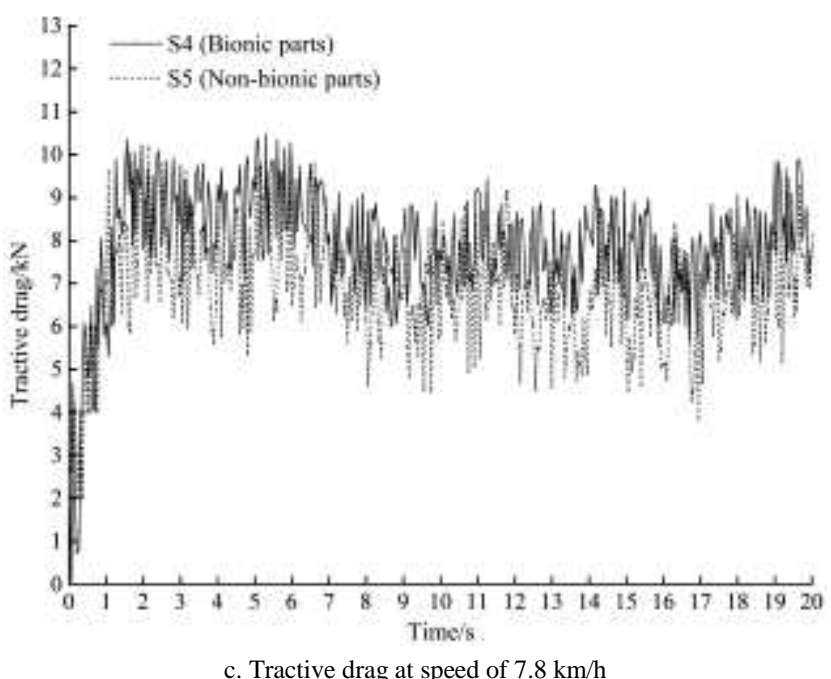

Figure 12 Results of the tractive drag

To sum up, the peak tractive drag of S4 was smaller than that of S5 by $13 \%-19 \%$. These results suggest that the bionic structures based on hare claw toes and bionic anti-drag surface more quickly destroyed the cohesion binding bonds and accelerated soil failure, further decreasing the peak drag ${ }^{[24]}$. However, along with the increase of the working speed, the non-bionic tilling and soil preparation machine induced soil failure more quickly. Thus, the difference between them was gradually narrowed down with the acceleration of the working speed.

After the stabilization, the tractive drag of S4 was far smaller than that of S5 under at the same speeds. The bionic structures had higher more pronounced anti-drag effects. The continuity of the water films, which formed upon the contact areas between soils and shovel surfaces, reduced soil cohesion, followed by the decrease of conglutination of the soil onto shovel surfaces, resulting in the decline of friction between the soil and tilling preparation parts.

\section{Conclusions}

(1) Compared with conventional tillage (CT), the shallow-loosening (SL) significantly raised the soil temperatures within the depth range $0-25 \mathrm{~cm}$ by loosening the soils. Specifically, the soil temperature increased by $0.7^{\circ} \mathrm{C}, 1.3^{\circ} \mathrm{C}$, and $1.1^{\circ} \mathrm{C}$ at a soil depth of $5 \mathrm{~cm}, 15 \mathrm{~cm}$, and $25 \mathrm{~cm}$, respectively. The reshaping ridge (RR) effectively increased soil temperatures within the depth range $0-15 \mathrm{~cm}$, which was attributed to the repair of the ridge shapes and the increase of the illumination areas on soil surfaces. The soil temperature increased by $0.5^{\circ} \mathrm{C}$ and $0.6^{\circ} \mathrm{C}$ at the depths of $5 \mathrm{~cm}$ and $15 \mathrm{~cm}$, respectively. As the soil depth gradually increased, the temperature-rising effects of both parts were slowly weakened, especially at the depth of $35 \mathrm{~cm}$. Based on the rise of soil temperature, the SL and RR both efficiently facilitated soybean development (seedling height).

(2) The 2BGD-6(110) bionic wide-ridge bean tillage-sowing machine simultaneously performed shallow-loosening, reshaping ridge, and sowing. A significant reduction was achieved in the tractive drag as compared with the conventional tillage-sowing machine due to the use of bionic tilling preparation parts. At the working speeds $5.3 \mathrm{~km} / \mathrm{h}, 6.5 \mathrm{~km} / \mathrm{h}$, and $7.8 \mathrm{~km} / \mathrm{h}$, the reduction of the tractive drag was by $1.69 \mathrm{kN}, 1.48 \mathrm{kN}$, and $1.37 \mathrm{kN}$, respectively, and the decreasing amplitude was within 13\%-19\%. These results suggest that the use of a hare claw toe bionic structure and bionic anti-drag surface could accelerate soil failure and thereby further decrease the peak drag. However, along with the increase of the working speed, the conventional tillage-sowing machine also induced soil failure within a shorter time. Therefore, the differences between the effects of the application of these machines were reduced with the acceleration of the working speed.

\section{Acknowledgments}

We acknowledge that this work was financially supported by Key Project Supported by the 13th Five-Year Plan for National Science and Technology (2016YFD0700302); National Natural Science Foundation of China (51705194) and technology development project of Jilin province (20160309001NY, 20190301023NY).

\section{[References]}

[1] Zhang Q P, Wang Z N, Miao F H, Wang G L. Dryland maize yield and water-use efficiency responses to mulching and tillage practices. Agronomy Journal, 2017; 109(4): 1196-1209.

[2] Jia H L, Zhang Z, Chen Z, Zheng T Z, Zhao J L, Guo M Z. Friction wheel transmission of no-tillage corn planters. Int J Agric \& Biol Eng, 2017; 10(4): 87-97.

[3] Liu T J, Xu X T, Yang J. Experimental study on the effect of freezing-thawing cycles on wind erosion of black soil in Northeast China. 
Cold Regions Science and Technology, 2017; 136: 1-8.

[4] Shan C G, Ni D P, Zhang F, Han J L, Wang X C, Zhu Y W, et al. Influences of several ridge culture patterns on growth of Salvia miltiorrhiza Bge root. Research and Practice on Chinese Medicines, 2017; 31(3): 1-4. (in Chinese)

[5] Ma L, Li C H, Fu J, Guo X L, Zhao X, Gao C, et al. Effects of ridge planting on the photosynthetic characteristics and yield of summer maize in high yield field. Acta Ecologica Sinica, 2011; 31(23): 7141-7150. (in Chinese)

[6] He J, Li H W, Zhang X M, Li W Y, Zhang X R. Design and experiment of 1QL-70 bed former for permanent raised beds. Transactions of the CSAM, 2009; 40(7): 55-60. (in Chinese)

[7] Tucker C. Reduction of air-and liquid water-filled soil pore space with freezing explains high temperature sensitivity of soil respiration below $0 \mathrm{C}$. Soil Biology and Biochemistry, 2014; 78: 90-96.

[8] Laudicina V A, Palazzolo E, Catania P, Vallone M, García A D, Badalucco L. Soil quality indicators as affected by shallow tillage in a vineyard grown in a semiarid mediterranean environment. Land Degradation \& Development, 2017; 28(3): 1038-1046.

[9] Ren L Q, Han Z W, Li J J, Tong J. Effects of non-smooth characteristics on bionic bulldozer blades in resistance reduction against soil. Journal of Terramechanics, 2002; 39(4): 221-230.

[10] Ma F L, Zeng Z X, Gao Y M, Liu E Y, Xue Q J. Research status and progress of bionic surface drag reduction. China Surface Engineering, 2016; 29(1): 7-15. (in Chinese)

[11] Guo Z J, Zhou Z L, Zhang Y, Li Z L. Bionic optimization research of soil cultivating component design. Science in China Series E: Technological Sciences, 2009; 52(4): 955-965.

[12] Li W W, Wen X X, Han J, Liu Y, Wu W, Liao Y C. Optimum ridge-to-furrow ratio in ridge-furrow mulching systems for improving water conservation in maize (Zea may L.) production. Environmental Science and Pollution Research, 2017; 24(29): 23168-23179.

[13] Freschi P, Fascetti S, Musto M, Cosentino C, Paolino R, Valentini V. Seasonal variation in food habits of the Italian hare in a south Apennine semi-natural landscape. Ethology Ecology \& Evolution, 2016; 28(2): $148-162$

[14] Zhang J B, Tong J, Ma Y H. Design and experiment of bionic anti-drag subsoiler. Transactions of the CSAM, 2014; 45(4): 141-145. (in Chinese)

[15] Zhang Y, Sun Y H, Ren L Q. Research on soil animals for the bionic analysis to abort bit bailing. Exploration Engineering, 2003; 30(2): 41-43 (in Chinese)

[16] Meyer W, Liumsiricharoen M, Suprasert A, Fleischer L G, Hewicker-Trautwein M. Immunohistochemical demonstration of keratins in the epidermal layers of the Malayan pangolin (Manis javanica), with remarks on the evolution of the integumental scale armour. European Journal of Histochemistry: EJH, 2013; 57(3): 172-177.

[17] Cong Q, Ren L Q, Wu L K, Chen B C, Li A Q, Hu A L. Taxonomic research on geometric non-smooth animal surface shapes. Transactions of the CSAE, 1992; 2(8): 7-12. (in Chinese)

[18] Ramakrishna A, Tam H M, Wani S P, Long T D. Effect of mulch on soil temperature, moisture, weed infestation and yield of groundnut in northern Vietnam. Field Crops Research, 2006; 95(2-3): 115-125.

[19] Radhakrishnan R, Kumari B D. Influence of pulsed magnetic field on soybean (Glycine $\max$ L.) seed germination, seedling growth and soil microbial population. Indian Journal of Biochemistry \& Biophysics, 2013 50(4): 312.

[20] Kovács Z, Szegedi A. Effect of front axle suspension on traction parameters of tractor with mechanical front wheel drive. Scientific Bulletin Series C: Fascicle Mechanics, Tribology, Machine Manufacturing Technology, 2015; 29: 57.

[21] Kang S Z, Hu X T, Goodwin I, Jerie P. Soil water distribution, water use, and yield response to partial root zone drying under a shallow groundwater table condition in a pear orchard. Scientia Horticulturae, 2002; 92(3): 277-291.

[22] Araghi A, Mousavi-Baygi M, Adamowski J. Detecting soil temperature trends in Northeast Iran from 1993 to 2016. Soil and Tillage Research, 2017; 174: 177-192.

[23] Tylkowski T, Bujarska-Borkowska B. Effect of acorn size and sowing depth on Quercus robur and Q. petraea seedling emergence and height. Sylwan, 2011; 155(3): 159-170.

[24] Botta G F, Tolon-Becerra A, Tourn M, Lastra-Bravo X, Rivero D Agricultural traffic: Motion resistance and soil compaction in relation to tractor design and different soil conditions. Soil and Tillage Research, 2012; 120: 92-98. 